\title{
Homenagem à memória de Waldemar Ferreira no Centenário de seu nascimento
}

\begin{abstract}
A Congregação desta Faculdade prestou homenagem, em 2 de dezembro, à memória do prof. Waldemar Ferreira. Juntamente com o Instituto de Direito Comercial Comparado e Biblioteca Tullio Ascarelli realizou uma sessão solene. Nesta se outorgaram os prêmios concedidos pelo Instituto, no concurso de monografias de direito mercantil de 1985, ao bacharel Fernando Boiteux e ao livre-docente Manuel de Figueiredo Ferraz.

Estavam presentes professores desta Casa, familiares do homenageado e muitos seus admiradores. Foi orador da sessão o prof. emérito Philomeno J. da Costa, cujo discurso é reproduzido a seguir. Também falou, agradecendo a homenagem, o deputado federal Herbert Levy.
\end{abstract}

RESUMO: Em 2 de Dezembro de 1985 transcorreu o centenário do nascimento do Prof. Waldemar Ferreira. O Instituto de Direito Comercial Comparado e Biblioteca Tullio Ascarelli fez coincidir nessa data, homenageando a memória do mestre, a entrega dos prêmios aos vencedores do concurso de 1985 de monografias inéditas de direito mercantil.

Foi orador oficial o professor emérito Philomeno Costa e falou também em nome da família do Prof. Waldemar Ferreira, o seu genro, o deputado Herbert Levy.

Foram declarados vencedores do concurso o dr. Fernando Netto Boiteux, com o seu trabalho sobre "Oferta Pública de Áquisição de Controle de Companhia Aberta" e o livre-docente Manuel Martins de Figueiredo Ferraz, sobre "Aspectos Jurídicos do Comércio na Grécia Antiga".

O culto à memória de Waldemar Ferreira iniciou-se com a análise da sua personalidade como mestre. A labuta do professor foi comparada ao mecanismo da punição de Sísifo de levar sempre uma rocha para o alto da montanha, que durante a noite caia para baixo. Invocou-se a figura ideal do professor universitário traçada por Savigny, em 1832, segundo o testemunho de Franco Casavola: seria utópico o seu alcance, mas Waldemar Ferreira "era assíduo e sabia arrolar os elementos, com que fazia seus alunos compreenderem os institutos sucessivos, acantonados didaticamente num direito mercantil histórico"; "o mestre ensinava mesmo, mas cujo ensino cobrava com exatidão nas provas escolares". Criou o Instituto de Direito Comercial, que então o homenageava. 
$\mathrm{O}$ culto à sua memória prosseguiu com a análise da personalidade de Waldemar Ferreira como advogado. "Cáustico na identificação dos fatos, tinha modos de não utilizar argumentos "ad hominem". Recebeu em 1956, o mais alto galardão do Instituto dos Advogados Brasileiros: o Prêmio Teixeira de Freitas. Em 1958 na 1ª Conferência Nacional da Ordem dos Advogados do Brasil a sua "Arte de Advogar"; aconselhava: o profissional insurge-se contra os atos dos magistrados, mas jamais contra os magistrados. A profissão do advogado - a mais nobre segundo Voltaire - é como a mulher querida; ela tanto mais se engrandece quanto mais é dignificada.

Waldemar Ferreira como jurista, segundo Levi Carneiro, teve uma produção bibliográfica muito grande, capaz de preencher páginas seguidas da "Revista da Faculdade de Direito". I - Sintetiza-se preliminarmente a questão centenária da autonomia do direito comercial. II - O homenageado foi sempre ferrenho defensor da sua autonomia científica. $O$ máximo que tolerou a respeito foi "A elaboração do conceito de empresas para extensão do âmbito do direito comercial" no VI Congresso Jurídico Nacional em 1955. Admitiu que na empresa se podiam aninhar atividades industriais, agrícolas, pecuárias e imobiliárias, mas tudo num campo à parte da vida dos negócios. Mas, com efeito, cada ato negocial se pratica na realidade jurídica do mesmo modo, quer o agente seja empresário ou não. $\mathrm{O}$ destaque especial de Waldemar Ferreira como jurista é, seu "Tratado de Direito Comercial" em 15 volumes. Ele divide a história desse direito em três períodos: (1756-1835) = Vida de José Maria Lisboa, $(1861-1930)=$ Vida de José Xavier Carvalho de Mendonça e $(1885-1964)=$ Vida de Waldemar Ferreira.

Finalmente a análise da personalidade como político de Waldemar Ferreira destaca o seu papel de início em prol da instituição entre nós do voto secreto, acabando-se com as atas eleitorias falsas. Sobressaiu-se com a formação sucessiva do Partido Democrático e com o Partido Constitucionalista que dirigiu. No movimento Constitucionalista de 1932 foi secretário do Governador Pedro de Toledo. Desejava-se patrioticamente a extinção do então governo ditatorial de Getúlio Vargas, encerrado pouco tempo depois.

Ainda na Faculdade de Filosofia da Universidade de São Paulo não se escreveu tese de doutorado, que pormenorize o belo período do mais puro brasileirismo dos paulistas entre 1924 e 1964 . Implantava-se a verdadeira democracia no Brasil. Ninguém trabalhou tanto para isto como o gigante do saber jurídico e esse patriota incorrigível, que foi Waldemar Ferreira.

1 - Hoje, 2 de dezembro de 1985, transcorre o centenário do nascimento do grande Waldemar Martins Ferreira, cuja memória vamos cultuar. Fizemos coincidir esta data com a outorga dos prêmios aos vencedores do concurso livre de monografias de direito mercantil, que o Instituto de Direito Comercial passou a promover todos os anos. O certame intelectual teve de resto o patrocínio 
da família do nosso querido homenageado. Ela entregou o numerário correspondente aos prêmios concedidos.

Estamos reunidos é verdade para aproveitarmos a data centenária de quem foi o melhor e o maior mestre de direito comercial do primeiro século de existência desta nossa "velha sempre nova Academia". Mas esta reunião solene deste Instituto de Direito Comercial, órgão anexo ao Departamento de Direito Comercial desta Faculdade, tem também o carisma da sua douta Congregação. Esta, com a sua autoridade, fez sua esta comemoração à memória de um dos seus mais ilustres componentes.

Falamos portanto menos como um dos componentes da Comissão Examinadora do concurso e de dirigentes desse órgão anexo ao Departamento de Direito Mercantil. Vamos tentar manter-nos à altura do nível da nossa representação maior.

2 - Numa ordem crescente de alusões a diversos assuntos, que abordaremos, aludiremos de início ao concurso, que neste ano se realizou sob os auspícios do culto à memória de Waldemar Ferreira.

O Instituto Brasileiro de Direito Comercial Comparado e Biblioteca Tullio Ascarelli, durante o período normal das aulas nesta Escola, realiza reuniōes quinzenais para o debate de assuntos momentosos, conseguindo que especialistas prestem assim a sua colaboração. Com o aparecimento da nova lei do cheque $\mathrm{n}^{\mathrm{0}} \mathbf{7 . 3 5 7}$, de 2 de setembro último, vimos mantendo em caráter excepcional reuniōes semanais. O dr. George Marcondes Coelho de Souza realiza um trabalho detalhado sobre esse título de crédito bancário, que será publicado na nossa "Revista de Direito Mercantil". Esta constitui também uma das atividades deste Instituto, coordenada pelo prof. Fábio Konder Comparato. Não faz muito veio à lume o seu no 57, correspondente ao primeiro trimestre de 1985 . Estamos no décimo quinto ano de publicação contínua, após uma interrupção decorrente da morte de Waldemar Ferreira, fundador da revista.

Podemos destarte registrar a particularidade de que os simpatizantes do direito comercial mantêm um culto da sua disciplina, quer pelos seus debates quinzenais dos seus temas mais interessantes, quer pelos escritos na sua revista especializada. E esses simpatizantes do direito dos negócios estabeleceram também o concurso anual de âmbito nacional, para trabalhos jurídicos inéditos, versando qualquer assunto desse campo jurídico negocial das atividades privadas dos cidadãos.

3 - E, como dissemos, devemos dar de início aos resultados do Concurso Waldemar Ferreira. 
Foram oferecidas sete monografias. A sua Comissāo Examinadora composta do orador, que ora lhes dirige a palavra, do professor titular Luiz Gastāo Paes de Barros Leães e do bacharel George Marcondes Coelho de Souza que, durante bastante anos, lecionou com proficiência e disciplina na Faculdade de Direito da Universidade Mackenzie. Verificou-se que a maioria dos trabalhos carecia de uma exposição contínua, pelo menos média, dos respectivos temas.

Surgiu logo um antagonismo de comportamento para os examinadores dos trabalhos. Eles tinham a faculdade de exigirem um certo rigor nos escritos. Estes deveriam ter uma esquematização dos elementos convergentes no caso específico; seguir-se-ia a referência dos autores e dos julgadores que se manifestaram a respeito; seria a revelação da pesquisa necessária; far-se-ia a sua crítica ou o seu apoio, como a parte substancial do desenvolvimento da tese; no fim, viriam as conclusões respectivas. Era o comportamento que os examinadores esperavam, agindo sob o ponto de vista da exigência de rigor. Este rigor varia e todos concordaram com que ele deveria ser carinhoso.

A outra ponta do antagonismo de comportamento para os examinadores era a conservação do estímulo aos juristas novos. Em lugar de se fazer prova de que teriam sido poucos os escritores, que opinaram sobre a matéria, aquiesceram os três que bastariam análises sumárias de uns poucos. Mas mantinham a esperança de que os candidatos mencionassem jurisprudência sobre o tema do trabalho.

Aconteceu entretanto de um modo geral que a pouca jurisprudência citada se fez pelas transcrições separadas dos acórdãos, engrossando sem razão a aparência do número das páginas escritas e sem a relevância do que o decidido significou. Aconteceu que houve trabalhos, fazendo referência expressa a autores estrangeiros, que eram reprodução de citações feitas por autores nacionais, sem o esclarecimento indispensável de que seriam referências de segunda māo; e essas citações não se conciliavam com o teor do desenvolvimento da matéria. Aconteceu em alguns trabalhos que o autor se desviou para assuntos supostamente paralelos, sem conexão com o encaminhamento do raciocínio para explicaçōes sem conexão.

Resultou que a Comissão Examinadora procurou não só aliviar a exigência de uma certa profundidade de cada tema como também achou que a repetição anualmente dos concursos de direito mercantil devia manter uma brandura encorajadora da produção de novos trabalhos.

As conclusões tinham que ser aquelas que adotou: a) - recusa da atribuição do primeiro prêmio; b) - escolha, como segundo prêmio, de um trabalho sobre a negociação do controle das ações de sociedade anônima de capital aberto; c) - acolher um tema sobre o comércio em épocas remotas, revelador de 
conhecimentos pelo seu autor, merecedores de encômios. A fortuidade de se desejar salientar um outro trabalho com nexo e de interesse relevante para a coletividade, mostrou recompensadamente que um estudante de direito fez uma análise jurídica de técnicas úteis; não sendo bacharel, como se exigia no regulamento do concurso, nem pôde receber menção honrosa.

A Comissão Examinadora outorgou enfim o segundo prêmio de $\mathrm{Cz} \$ 2.000 .000$ ao tema do advogado Fernando Boiteux, do Rio de Janeiro, versando "Oferta pública de aquisição de controle de companhia aberta". Concedeu a mesma Comissão menção honrosa ao trabalho do professor livre-docente desta Casa, Manuel Martins de Figueiredo Ferraz, cuidando de "Aspectos jurídicos do comércio na Grécia Antiga".

O novo direito das sociedades por ações, criado pela Lei no 6.404 , de 15 de dezembro de 1976, reconheceu entre nós o valor distindo de que pode revestir-se o poder do acionista controlador da companhia. A luta oficial pela sua negociação está na oferta públlica da sua aquisição, regulada nos arts. 257 a 263. É sabidamente o "take over bid" originariamente dos ingleses. Trata-se de um capítulo deveras importante da mecânica do controle das companhias de capital aberto.

Sempre existiu o respeito natural pelas liçōes dadas pelo helenismo, sob a preponderância artística e literária de Atenas, mesmo com a decadência política iniciada com a Guerra do Peloponeso contra Esparta, começada por Péricles no auge do seu poderio, no Sec. IV a.C. Os estrangeiros ambiciosos, que conseguiam fixar-se em Atenas - os metécos - impulsionavam o comércio marítimo e o terrestre, gerando formas contratuais novas, da mesma forma como se passa com os dias de hoje. Vem à mente aquela imagem feliz, comparando a Civilização a uma árvore frondosa. Os seus galhos e as suas folhas só se desenvolvem na medida em que as raízes penetram no solo. A erudiçāo, revendo exemplificativamente os antiquíssimos institutos chamados mais tarde pelos romanos de Lei de Rodes do Alijamento e do Empréstimo Marítimo, colabora na análise das raízes, que mantêm o tronco da empresa moderna, encarada sob o ponto de vista jurídico.

Estão dadas destarte as explicações do comportamento da Comissão Examinadora do Concurso de monografias de direito comercial.

4 - Passamos a cultuar a memória de Waldemar Ferreira. Fazemô-lo inicialmente como o professor. A sucessão contínua das gerações cria a necessidade da transmissão do conhecimento humano pelos mais idosos aos mais jovens. Em todos os dias nascem novos seres e em todos os dias os velhos partem para o além. A economia dos vivos, isto é, o seu sistema de vida, aprimora-se com o aproveitamento das conquistas da Ciência e das aplicaçōes da Tecnologia. Nas lendas gregas há a figura de Sísifo, célebre pelas suas malandragens; 
fundador, ao que se diz de Corinto, localizada na nesga de terra que ligava a Grécia propriamente dita ao Peloponeso, Sísifo extorquia os viajantes, que transitavam pelo istmo. Foi afinal morto por Teseu, o herói das mil aventuras da época. Sísifo foi condenado pelos seus crimes a rolar sempre uma rocha enorme até o alto de uma montanha, de onde sempre caia ao chegar ao seu cimo. E o rolar da rocha acima sempre se renovava.

Por aquilo que dissemos, queremos logo comparar o trabalho dos mestres à punição de Sísifo. $\mathrm{Na}$ lenda se destaca a política do castigo merecido. $\mathrm{Na}$ realidade dos nossos dias há a indispensabilidade do ensino para a sustentação da Ciência e da Tecnologia. Se as transmissões do Conhecimento, pelos que sabem àqueles que aprendem, se interromper, a Civilização recuará. Quando um professor consegue deixar no alto os seus aprendizes, retorna e sempre, aos baixios como novo grupo para levá-lo para cima. A pedra de Sísifo simboliza historicamente a punição do malandro. E, por comparação mecânica, a pedra de Sísifo concretiza o tipo de renovação perene da transmissão do Saber.

A noção de castigo confunde-se pela nossa comparação com a gratificaçāo da virtude. É que o ensino se rodeia de requisitos intelectuais e morais que o eleva à condição de retidão e de probidade. Sua atuação autêntica é uma excelência moral. Se para Sísifo o rolar para cima da rocha foi punição, a elevação dos neófitos para as alturas do Saber constitui uma recompensa. São iguais apenas na constância da labuta de guindagem para o alto das coisas ou dos aprendizes. A rocha é sempre a mesma no caso de Sísifo e ela é cada vez outra sempre que o professor carrega para o alto os seus catecúmenos.

O professor universitário deve ter várias qualidades para concentrar o respeito dos seus colegas e dos seus alunos.

O professor de direito romano Franco Casavola tem uma crônica muito douta sobre história do direito romano. Foi um modo erudito de revelar a Storia del Diritto Romano, na sua quarta edição (póstuma) do grande Pietro Bonfante. Essa crônica está em Labeo, revista quadrimestral desse ramo do direito, nas págs. 305 a 325 do volume correspondente ao ano de 1959, publicada pela Editora Jovene, de Nápolis. O importante para nós é que Casavola iniciou o seu escrito substancioso, ao destacar a opiniāo de Savigny, em 1832, traçando a figura ideal do professor universitário.

Franco Casavola escreve logo que Savigny não registrava como méritos principais de um mestre ser autor de descoberta científica, possuir o encanto da eloqüência fácil e clara, ter a seriedade e a diligência no desempenho de suas atividades ou possuir a solicitude para incentivar os alunos. Savigny considerava sobremodo que, no seu ver, o professor universitário devia ter uma grande força de comunicação, com toda a sua personalidade e incutir no acadêmico o espírito da ciência. Savigny considerava o professor universitário ideal aquele 
que conseguisse penetrar com toda a sua personalidade, no convencimento do discípulo, de tal modo que este se compenetrasse do espírito da ciência que aprendia.

É germanicamente um ideal de perfeição. Seria como se todos os ex-alunos saíssem das faculdades de direito como outros tantos Fredericos Carlos von Savigny ou outros tantos Waldemares Martins Ferreira.

É utópico.

Não fomos alunos do mestre agora homenageado. Mas pela identidade de idéias políticas e pela amizade com seus antigos alunos, e com ele mesmo, pudemos capacitar-nos de que Waldemar Ferreira era assíduo e sabia arrolar os elementos, com que fazia seus alunos compreenderem os institutos sucessivos, acantonados didaticamente num direito mercantil histórico. $\mathrm{O}$ testemunho dos seus discípulos foi que o mestre ensinava mesmo, mas cujo ensino cobrava com exatidão nas provas escolares. Isto é ser professor.

Podemos acrescentar, como preito de jstiça, que Waldemar Ferreira tinha a facilidade da explicação; ele mantinha a seriedade no ensino da sua matéria que conhecia a fundo; os seus estudantes, diziam na sinceridade dos seus juízos, que o direito mercantil era uma coisa simples, ao contrário de outras disciplinas jurídicas que se lhes afiguravam mais difíceis.

Na homenagem póstuma desta douta Congregação da Faculdade de Direito, neste mesmo Salão Nobre, em 10 de setembro de 1964, Sylvio Marcondes, seu sucessor ilustre na cátedra, escreveu, como se lê na Revista da Faculdade de Direito, vol. LX (1965), pág. 52 e como sendo síntese de Waldemar Ferreira professor universitário: “Averiguar sem paixão a verdade, para poder amá-la apaixonadamente. Informar para orientar, propondo sem imposição. Trazer para a luz a lição objetiva da sabedoria, esquecendo na sombra a energia dispensada na sua procura. Não se apegar ao ortodoxo, apenas porque ortodoxo e, ao contrário, favorecer o livre exame das idéias renovadoras. Não expor a ciência como algo esotérico e obscuro e, sim, fazer da palavra o retrato fiel dos conceitos, sem sacrificar pelo rebuscado do verbo, a clareza do pensamento. Animar os pessimistas, trabalhar em otimismo, infundir confiança".

Nāo desejamos quebrar o tom respeitoso da nossa homenagem, mas como é que qualquer pessoa, nāo conhecendo Waldemar Ferreira, poderia identificá-lo com toda a segurança no meio dos professores seus colegas?

Referiam-se os estudantes à "gravatinha borboleta do Waldemar". Sempre a usou, tal como, posteriormente, o fez o nosso querido Moacyr Amaral Santos. Saiu da moda a gravata de laço borboleta, mas Waldemar Ferreira nunca a 
abandonou. E se identificava assom com o seu ar de bonhomia, quando as coisas andavam direitas.

Nós, não possuimos dons carismáticos para convencermos os nossos ouvintes, mas lhes apresentamos, como uma das pontas da liberdade de raciocínio de cada um, a versão autêntica de que Waldemar Ferreira foi um grande professor universitário. Foi ele quem criou e dirigiu os primeiros passos deste Instituto Brasileiro de Direito Comercial e Biblioteca Tullio Ascarelli.

5 - Passamos a cultuar em seguida a sua memória como o advogado.

Este é o profissional que começa por viver sentindo dia-e-noite uma chama interna crepitando-lhe o seu íntimo. Tem que senti-la e não pode absolutamente dela dar demonstraçōes. $\mathrm{O}$ advogado tem que ser essencialmente educado. Para tanto deve externamente trajar-se convenientemente; pode muito bem até usar gravata de laço borboleta, revestindo a sua postura de um ar feliz. Chega-se a este estágio depois de se passar um qüinqüênio, ouvindo aulas de Direito. Para aqueles que se voltarāo para o exercício da advocacia, a convivência acadêmica constitue a massa que vai moldando o profissional brioso. Muitos não o são. Paciência. Ficam vegetando nos empregos públicos, obtidos no início como ajuda do aprendizado, que na realidade não se faz. Só é advogado quem lê e quem estuda, além de possuir o espírito de combate, nome diferente da chama interna que o anima.

Ora Waldemar Ferreira era lutador. Briguento educado. Cáustico na identificação dos fatos, tinha modos de não utilizar argumento "ad hominem". Vimos profissionalmente uma sua interpelação judicial contra um vendedor inadimplente; o preço subiu e o interpelado deixou de entregar a mercadoria, como acontece. A peça advocatícia utilizava palavras-lâminas ou ponteagudas, para caracterizar a inadimplência. Mas quando se dirigia ao inadimplente escrevia que ele saberia compreender as conseqüências da sua falta. Os profissionais, menos elegantes, logo catologam os adversários dos seus clientes com arranhaduras. Waldemar não melindrava o adversário do seu constituinte, o que era um sinal da sua alta classe. Quando o colega contrário não sabia manter a linha, Waldemar então o tratava no processo com o sarcasmo refinado de quem, tendo cultura, desnudava os botes "ex adverso".

Devemos aludir em particular a dois fatos que indicam o mais alto grau profissional alcançado por Waldemar Ferreira.

Ele recebeu, em 29 de novembro de 1956, o Prêmio Teixeira de Freitas. Era o mais alto galardão que o Instituto dos Advogados Brasileiros outorgava então aos mais destacados colegas. 
Devemos salientar que a proposta da outorga do prêmio partiu do grande Levi Carneiro; este, no mesmo dia em que se empossava o premiado no Instituto, tinha a elegância de recordar pelas colunas do vetusto "Jornal do Comércio" que fora o iniciador da recompensa, aceita sôfrega e unanimemente pelos conselheiros do sodalício. Essa recordação tão distinta está reproduzida na Revista dos Tribunais, vol. 267, págs. 777 e segs. Dela destacamos trecho da proposição inicial de Levi Carneiro: "O sr. Waldemar Martins Ferreira, há pouco encerrou por jubilação compulsória, motivada pela idade, sua atividade de professor catedrático da Faculdade de Direito da Universidade de São Paulo, onde durante cerca de trinta anos, regeu com a maior competência a cátedra de direito comercial. Ao mesmo tempo, a partir de 1919, até agora, publicou especialmente sobre essa matéria, numerosas e notáveis obras de merecimento comentários da jurisprudência, pareceres, análises e críticas das instituições, história e comentário da legislação. Pode resumir-se o valor de seu imenso e fecundo labor, nesse setor, dizendo que ele recebeu e avultou a sucessão de José Xavier Carvalho de Mendonça...". Mais adiante se lê: "Toda essa vasta obra erudita e conscienciosa enche uns cincoenta volumes na "Revista da Faculdade de Direito de São Paulo". A de nenhum outro jurista brasileiro vivo será mais numerosa e extensa, nem mais benemérita e valiosa. Nenhum terá prestado mais relevantes serviços à difusāo e ao fortalecimento da cultura jurídica nacional. Raros se poderão comparar-lhe".

Foi pela advocacia que ele entrou para o rol dos grandes nomes da ciência jurídica, já que a mais autorizada grei da profissão o reconheceu, o proclamou e o gratificou.

$\mathrm{O}$ outro fato do maior relevo, que devemos assinalar em Waldemar Ferreira como advogado, constitui a sua "Arte de Advogar". Realizou-se em agosto de 1958 a Primeira Conferência Nacional da Ordem dos Advogados do Brasil. O segundo tema da sua Segunda Comissão consistiu exatamente na análise do ofício do defender ou de atacar uma causa em juízo. Waldemar Ferreira, como seu relator, produziu "A arte de advogar", que por sinal está dependendo de uma divulgação maior. Encontra-se na Revista da Faculdade de Direito de $\mathbf{S}$. Paulo, no segundo fascículo do volume 54 (de 1959) págs. 86 e segs. As suas três partes são: I - A linguagem Forense e o estilo; I - Os argumentos de autoridade e o eruditismo e III - A comunicação dialética do advogado com o juiz. A - A eloqüência é a melhor linguagem forense. B - Nāo se contentando com os seus próprios conhecimentos, o advogado deve ostentar erudição, invocando os argumentos de autoridade. C - E se insurja contra os atos dos magistrados, mas jamais contra os magistrados; a dialética desenvolve-se em regime de cortesia, de lealdade, de respeito e sobretudo de dignidade humana. E a síntese da lição tripla da arte de advogar.

A profissão do advogado, a mais nobre no dizer insuspeito de Voltaire, pode ser comparada à mulher querida, linda e companheira; ela tanto mais se 
engrandece quanto mais é dignificada. Num ponto os filhos de Adão perdem de longe para as filhas de Eva. Quando estas são respeitadas, elas devolvem o respeito com toneladas esmagadoras de carinho, sublimando o teor da vida dos mortais. Nunca a eloqüência do advogado, nunca a sua erudição e nunca o seu respeito aos juízes foram por estes ignorados.

6 - Passamos agora a cultuar a memória de Waldemar Ferreira como jurista. Relembramos aos nossos ouvintes que, ao tratar do nosso homenageado como o advogado, utilizamos palavras de Levi Carneiro, justificando a sua proposta da concessão da medalha de bronze Teixeira de Freitas; ele escreveu que a produção bibliográfica enchia as páginas contemporâneas do órgão oficial da douta Congregação desta Faculdade. Não se devendo fazer análises em detalhe, há a solução razoável do destaque da matéria importante da subsistência do direito comercial, sobre a qual se manifestou oficialmente o grande jurista.

I - Os comercialistas brasileiros da geração atual parece que diminuiram muito o seu interesse pelo problema da autonomia científica do direito comer$\mathrm{cial}^{(*)}$ de que o grande Teixeira de Freitas foi pioneiro; e pioneiro antes, muito antes da célebre aula inaugural de Vivante de 1888, em Bolonha e que manteve apesar da sua posterior apostasia, como peça inaugural do seu ainda ótimo Trattato di Diritto Commerciale. O mestre italiano mostrou que não se justificava mais a dualidade de um Código Civil e de outro Comercial.

Esta particularidade pode ser explicada em poucas palavras. A força expansionista do direito profissional dos comerciantes invadiu a caracterização do direito dos contratos civis. Há as normas jurídicas, que regulam as combinações particulares dos cidadãos entre si; existe assim uma regulamentação, que constitui no geral o direito civil. Podemos dizer também que existe um outro conjunto de regras entre pessoas, quando se trata de comerciantes ou de negócios que estes praticam entre si. Temos, singelamente, um direito civil de um lado e temos um direito comercial de outro lado. A soma do direito civil mais o direito comercial dá aquilo que se convencionou de chamar de direito privado. Nós ainda possuimos os restos do velho Código de Comércio de 1850. Nós temos um Código Civil, que vige desde 1917. Concluindo a exposição, temos um Código Comercial e temos um Código Civil.

(*) Uma observação, não incluída no texto da saudaçāo ao caro Mestre, consistia em que a predominância dos militares na direção política do País, a partir de 1964 , acarretou um seu desenvolvimento econômico acentuado; este repercutiu no aumento marcado de candidatos aos cursos de ensino superior. Essa predominância no campo educacional foi contudo bem infeliz. Improvisaram-se professores para dirigirem mal os estudantes piores preparados. Esses denominados docentes nāo estimariam achar que não haveria mais um direito comercial... para não perderem o emprego vistoso de "professor universitário"... 
A tranqüilidade desta exposição esbarra todavia com a circunstância já revelada de que o expansionismo do cirreito mercantil invadiu toda a parte das obrigações e contratos do direito civil. Este, sendo invadido por aquele, acabou sendo um direito comum dos dois.

Então se coloca a conclusão decisiva: o direito comercial passou a ser parte do direito civil, ou seja, antes existia a autonomia do direito comercial e agora há a unificação do direito privado.

Engalfinharam-se então os afirmados autonomistas e os referidos não autonomistas. Teixeira de Freitas foi praticamente, como já se disse, o primeiro não autonomista; quando se encontrava no final do seu Projeto de Código Civil, rescindiu o contrato com o Governo Imperial, para a então elaboração de um Código Civil para o Brasil.

Historicamente os antiautonomistas dizem que no fim da Idade Média se criou um direito profissional dos comerciantes. Depois se evoluiu para um direito dos atos comerciais. Era objetivamente comercial o ato assim considerado, embora não praticado por um comerciante; uma viúva, sacando cheque sobre a sua provisão no banco, praticava um ato comercial sem ser comerciante. Os autonomistas passaram a dizer que a generalização dos atos comerciais aos não comerciantes esquecia que sempre existe na vida privada dos negócios uma profissionalização, que se caracteriza por um núcleo de atividades repetitivas com objetivo de lucro. É a empr`ssa, é a constância da atividade mercantil. O comerciante individual ou qualquer sociedade de fins lucrativos atua em torno de certos bens (o estabelecimento), admitindo empregados e fazendo contratos. As pessoas leigas, embora tais, verificam que existem muitos negócios com enorme desenvolvimento e com grandes dimensões. São as empresas pequenas, médias, grandes e sobretudo as multinacionais. $\mathrm{O}$ velho direito comercial mantém-se então como sendo o direito da empresa. É o que afirmam os autonomistas.

II - Waldemar Ferreira manteve-se autonomista ferrenho. Consentiu apenas em admitir que o direito mercantil poderia ser um direito especial que, além das empresas comerciais e industriais, abrangeria aquelas agrícolas, as pecuárias e as imobiliárias. O curioso poderá ler o seu douto relatório de 14 de janeiro de 1955, no VI Congresso Jurídico Nacional sobre o tema "A elaboração do conceito de empresa para extensão do âmbito do direito comercial". Ele está reproduzido na Revista Forense vol. 231, de 1970, págs. 35 e segs. A Revista de Direito Mercantil (ano de 1955, nas primeiras 34 páginas) não só o reproduziu como também deu toda a discussāo havida na sessão da discussão do tema.

Quando se elaborou pela primeira vez um Código de Comércio, e foi na França, em 1807, já surgiram as empresas comerciais e manufatureiras; o nosso 
legislador mercantil de 1850 reproduziu esse aparecimento. Estamos sintetizando o pensamento central de Waldemar Ferreira. A empresa era já instrumento da atividade comercial ou industrial, que se caracterizava na exploração do estabelecimento. Então a empresa seria um segundo círculo concêntrico, em que o primeiro seria o estabelecimento e o terceiro seria o proprietário (comerciante individual ou a sociedade comercial). Waldemar Ferreira, como acentuou Sylvio Marcondes, no seu aludido elogio póstumo (Rev. Fac. Dir., vol. LX-1965 págs. 61-64), pensava essencialmente em isolar a empresa do fenômeno dinâmico da vida dos negócios, em que a sua centralização supera uma propriedade civil estática. Com a generalização da empresa, como centro que é de interesses múltiplos, dizemos nós, as práticas antes mercantis passavam a ser utilizadas quer por empresários, quer por todas as pessoas em geral. Não há mais distinções profissionais. Cada ato se prático no campo jurídico do mesmo modo sendo um empresário ou sendo um cidadāo qualquer a realizá-lo.

A linguagem técnica nāo é inteligível numa sua primeira enunciação. Podemos repeti-la sob um ponto de vista diferente. Antigamente se negociava bem mais a varejo do que por atacado. Na idéia do comércio, aproximada bastante de seu conceito em Economia Política, compreendia-se o deslocamento da mercadoria no espaço com o seu transporte. Antigamente se produzia pouco mais do que para o gasto e industrialmente se produzia sob encomenda. $\mathrm{O}$ círculo dos profissionais, envolvidos nesse modo da circulação das riquezas, mantinha regras jurídicas próprias. Depois a produção passou a ser em massa; a idéia do transporte das mercadorias perdeu a primitiva importância para a caracterização das atividades dos mercadores da Baixa Idade Média. A regulamentação profissional deles uniformizada pelos usos internacionais de então generalizavam-se aos não-comerciantes; a letra de câmbio, como um exemplo, deixou de ser uma carta ("lettera" em italiano) de um banqueiro ao seu colega no estrangeiro para pagar na moeda da praça do destino uma quantia ao portador e que o autor da carta já recebera em moeda da sua praça. A letra de câmbio deixou de ser uma operação de câmbio por banqueiro, para evoluir para a ordem de pagamento, que qualquer cidadão dá contra outrem em favor do terceiro nela indicado (ou do próprio emitente). Os costumes mercantis generalizavam-se aos não comerciantes, envolvendo toda a gente. As regras jurídicas dos profissionais antigos tornaram-se mandamentos comuns.

Mas estes mandamentos se alimentam da atividade dos negócios, persistem os autonomistas.

Eles observam que, se antes eram os mercadores e transportadores que figuravam como os personagens diretamente atuantes nos negócios, com a produção indiscriminada ou em massa, o primitivo estabelecimento comercial agigantou-se pra grandes entrepostos e fábricas com o concurso indispensável de um número grande de empregados. Resultou que aquele pequeno armazém de outrora pode ser e costuma não raro ser um imenso entreposto. Em torno dele 
giram operários, devedores, credores e o fisco para cobrar impostos e fiscalizar a mão-de-obra. Um simples depósito quieto agigantou-se para uma atividade plural enorme. Esquece-se até de quem seja o dono. Só se fala com empregados. Começou a generalizar no horizonte da Economia Política uma atividade concêntrica, produtora de riquezas. 'Uma fábrica não vale porque pertença a $\mathrm{A}$ ou a B. A fábrica vale pela continuidade da sua produção. É a empresa que conta.

O direito mercantil não seria mais direito comercial, mas continuaria distinto, porque passou a constituir o direito das empresas.

Waldemar Ferreira preferiu considerar esse assunto relevante sob o enfoque da distinção, com que todos estão de acordo, entre estabelecimento, empresa e proprietário da empresa.

Mas a separação do direito comercial do direito civil vingou enquanto os seus súditos mantinham regras distintas de relacionamento entre si e com os profanos, isto é, os não comerciantes. Desde que as regras mercantis se generalizaram, a indagação da classificação dos praticantes não alimenta uma diferenciaçāo entre empresários e não empresários.

$\mathrm{O}$ assunto é árido para os ouvintes. Registramos que a nossa primeira tese para concurso para professor de direito comercial nesta Casa cuidou exatamente da denegação da autonomia científica desse direito. Foi natural que desagradassse os nossos cinco fidalgos e doutos examinadores. Continuamos, não obstante, arraigados às nossas idéias, sem que a nossa admiração autêntica, constante e marcada por Waldemar Ferreira pudesse jamais diminuir. Os franceses dizem que "il est avec le ciel des accommodements".

Outra particularidade em Waldemar Ferreira como jurista é o destaque que necessitamos de dar à sua maior obra, que coroou a sua vida tão plena de labuta útil para a coletividade. É o seu monumental Tratado de Direito Comercial, com quinze volumes. Iniciou a sua publicação em 1960, que só terminou em 1966, sendo póstumos os três últimos volumes. Confessamos o nosso orgulho de tê-lo completo com a dedicatória espontânea e elevada do querido mestre em cada volume. Os cinco primeiros tratam dos sujeitos de direito mercantil. Os sexto e sétimo volumes ventilam o estatuto do estabelecimento e da empresa mercantil. $\mathrm{O}$ oitavo até décimo primeiro analisam os contratos mercantis e os títulos de crédito. Os décimo segundo e décimo terceiro volumes expõem o direito da navegação. $\mathrm{E}$, finalmente, os décimo quarto e décimo quinto volumes enfrentam a falência e a concordata.

Essa obra dividiu a história do direito comercial brasileiro em três períodos: 1ำ (1756-1835) corresponde à vida de José Maria Lisboa, Visconde de 
Cayru; 20 (1861-1930) relativo à vida de José Xavier Carvalho de Mendonça; e 30 (1885-1964) referente à vida de Waldemar Martins Ferreira.

As coisas, que se tornam religiosas, passam a ser apenas indicadas pelo seu nome singelo. O exemplo que mais nos toca é o Tratado de Direito Comercial.

7 - E passamos finalmente a cultuar a memória de Waldemar Ferreira como o político.

Moacyr Amaral Santos - o saudoso professor de processo civil e ministro do Supremo Tribunal Federal -, quando, na véspera da jubilação do nosso mestre, em 1ำ de dezembro de 1955, o Instituto dos Advogados de São Paulo o homenageou, preferiu analisá-lo não como o político mas como o cidadão (Revista da Ordem dos Advogados de Sāo Paulo, fasc. de dez. de 1955, nº 100, págs. 28-33). A diferença do trato é contudo apenas aparente. Moacyr extraia da massa aqueles que se posicionavam abstrata e ostensivamente como cultores do patriotismo. São dele estas palavras: "Cidadãos, num país politicamente bem educado, sāo os indivíduos que cumprem seus deveres cívicos". Repetia Duran y Ventosa. Nós já encaramos o cidadão por aquilo que fez politicámente.

Vamos dizer algo em poucas palavras, que desagradará talvez muitas pessoas. Não importa.

A Proclamação da República encontrou o povo boquiaberto. Depois que os militares, descontentes com o nosso velho Imperador, forçaram uma república quase sem republicanos, fortificou-se "A Corrupção Eleitoral pelo Suborno". Leia-se este capítulo de história de direito político colonial escrito por Waldemar Ferreira (Rev. Fac. de Direito, vol. LII, ano de 1957, págs. 65-71). As eleições realizavam-se por meio das atas falsas. O grupo, que no Estado de São Paulo dominava oligarquicamente a política, era o Partido Republicano Paulista, cujas iniciais, substantivadas, passou a ser o "perrepismo". As eleições constituiam uma autêntica vigarice. Quando a Liga Nacionalista de Frederico Vergueiro Steidel desfraldou a bandeira da adoção do voto secreto entre nós, perrepistas, como outros Balthazares, sitiados em Babilônia pelos persas do rei Ciro, riam dos patriotas, que sonhavam com a instalação de fato da república entre nós.

Waldemar Ferreira sobressaiu-se logo como o patriota sincero que com outros formaram o Partido Democrático e depois o Partido Constitucionalista. Foi, em São Paulo, o seu presidente. No Movimento Constitucionalista de 1932, o nosso homenageado foi o Secretário do Governador Pedro de Toledo.

Continua em aberto na Faculdade de Filosofia da Universidade de São Paulo a redação de teses de doutorado que pormenorisem o belo período do 
mais puro brasileirismo dos paulistas, medeando 1924 a 1964 . As muralhas, representadas pela Força Militar de apoio aos perrepistas, ruiu em 1930, acabando-se com os festins de Balthasar. Iniciava-se a luta para a implantação da democracia no Brasil. Vejamos se agora, sem os solavancos do militarismo, conseguiremos à custa de tantas eleiçōes enveredar pelo caminho da democracia autêntica.

Ninguém trabalhou tanto para isto como Waldemar Ferreira!

8 - Encerramos as nossas alongadas palavras. Genuflexos, dirigimos o nosso pensamento a esse gigante do saber jurídico e a esse patriota incorrigível! 